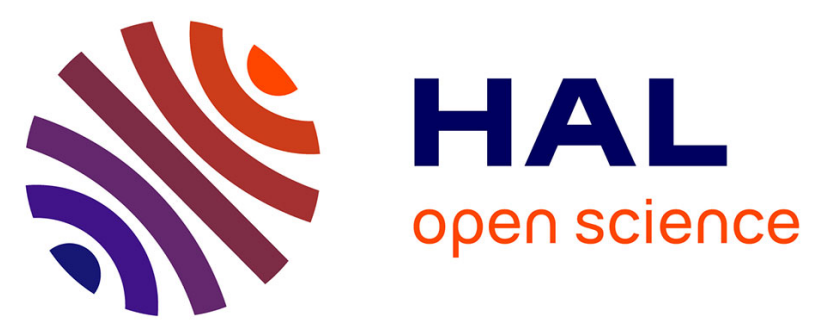

\title{
A Multi-criteria Approach to Collaborative Product-Service Systems Design
}

Martha Orellano, Khaled Medini, Christine Lambey-Checchin, Maria-Franca Norese, Gilles Neubert

\section{- To cite this version:}

Martha Orellano, Khaled Medini, Christine Lambey-Checchin, Maria-Franca Norese, Gilles Neubert. A Multi-criteria Approach to Collaborative Product-Service Systems Design. IFIP International Conference on Advances in Production Management Systems (APMS), Sep 2019, Austin, TX, United States. pp.481-492, 10.1007/978-3-030-29996-5_56 . emse-02278782

\section{HAL Id: emse-02278782 \\ https://hal-emse.ccsd.cnrs.fr/emse-02278782}

Submitted on 30 Jan 2020

HAL is a multi-disciplinary open access archive for the deposit and dissemination of scientific research documents, whether they are published or not. The documents may come from teaching and research institutions in France or abroad, or from public or private research centers.
L'archive ouverte pluridisciplinaire HAL, est destinée au dépôt et à la diffusion de documents scientifiques de niveau recherche, publiés ou non, émanant des établissements d'enseignement et de recherche français ou étrangers, des laboratoires publics ou privés. 


\title{
A multi-criteria approach to collaborative Product-Service Systems design
}

\author{
Martha Orellano ${ }^{1}$, Khaled Medini ${ }^{2}$, Christine Lambey-Checchin ${ }^{3}$, \\ Maria-Franca Norese $^{4}$, and Gilles Neubert ${ }^{5}$ \\ 1 Mines Saint-Etienne, Univ Lyon, Univ Jean Moulin, Univ Lumire, Univ Jean \\ Monnet, ENTPE, INSA Lyon, ENS Lyon, CNRS, UMR 5600 EVS, Institut Henri \\ Fayol, F-42023, Saint-Etienne, France. martha.orellano@emse.fr \\ 2 Mines Saint-Etienne, Univ Clermont Auvergne, CNRS, UMR 6158 LIMOS, Institut \\ Henri Fayol, F 42023, Saint-Etienne, France \\ 3 Univ Clermont Auvergne, EA3849 CleRMa, F-63008, Clermont-Ferrand, France \\ 4 Politecnico di Torino, DIGEP, Torino, Italy \\ ${ }^{5}$ emlyon business school, CNRS, UMR 5600 EVS, F-42009, Saint-Etienne, France
}

\begin{abstract}
The design of innovative systems involves a complex decision making process spanning over different criteria and stakeholders. The complexity of the design process is heightened at its early stages by data scarcity, involving high uncertainty and vagueness. Product-Service Systems (PSS), which are bundles of products and services designed to fit complex customer needs, are an example of those innovative systems. PSS design can be thus approached as a multi-criteria and multi-stakeholder decision process. The aim of this research is to provide a consistent framework for decision aiding in the early stages of collaborative PSS design. The framework was built within a collaborative project involving a French company, interested in innovative solutions for managing their safety clothing system. At the methodological level, the Analytic Hierarchy Process (AHP) was used.
\end{abstract}

Keywords: Collaborative innovation $\cdot$ PSS design $\cdot$ AHP

\section{Introduction}

Product-Service Systems (PSS) are bundles of products and services designed to improve competitiveness by satisfying customers needs during the entire life cycle of the offer [5]. Designing PSS requires a strong collaboration among several actors along the supply chain, aiming at creating higher value than in traditional offers [2]. Developing a collaborative PSS suggests that the value to be co-created should be clearly and explicitly defined (i.e., beyond economics, involving organizational and sustainability dimensions), and actors' expectations should be deeply understood [5]. Consequently, PSS design can be approached as a complex multi-criteria and multi-stakeholder decision process $[2,6]$. Several methodologies have been proposed in the literature to design and evaluate PSS offers. Most of the researches are concerned with the provider perspective, focusing on the operational design of PSS alternatives $[5,2,13,9,8]$. Few works 
consider the customer perspective in early phases of PSS design $[6,1,10,12]$. This research aims at exploring a customer perspective of early PSS design in the absence of a predefined set of PSS alternatives. An empirical research is carried out within a French company regarding its system of safety clothing. The adopted approach starts by identifying the customer needs and setting its objectives, then identifying the key actors, and finally, drawing out a set of possible alternatives in collaboration with the providers. The Analytic Hierarchy Process (AHP) method is implemented to support the decision process. Indeed, the aim of this research is to provide a consistent framework for decision aiding at the early phases of collaborative PSS design, integrating both provider and customer perspectives.

The structure of the paper is as follows. Section 2 presents briefly a literature review of Multi-Criteria Decision-Aiding (MCDA) approaches applied to PSS design. Section 3 introduces the AHP method, explaining the adequacy for early PSS design. Section 4 introduces the case study, describing the empirical approach and the application of AHP. The discussion is carried out in section 5 . Finally, conclusions and research perspectives are explained in section 6 .

\section{MCDA approaches for PSS design}

Decision aid has become an important axe of research in PSS literature, in particular during the last decade $[5,2,13,9,8]$. One of the main reasons why this research stream is gaining in importance, is the need of collaboration between several actors to develop PSS offers, seeking at the trade-off between their expectations [6,2]. Engaging a decision process depends on the time horizon, the availability and quality of data and knowledge, and the quality of key actors' relationships; elements that influence the level of decisions' effectiveness [2]. Additionally, making decisions in early stage of PSS design involves an important level of uncertainty, vagueness and subjectivity, induced by the lack of knowledge [6]. To deal with these issues, several researchers have used MCDA techniques. Most of researches focus on the provider perspective, being interested on the operational analysis and the design of a given set of PSS alternatives $[13,9,8,8]$. Methods such as TOPSIS and VIKOR have been used to choose PSS alternatives compared to an ideal solution, already available in the market [11]. In this case, decision approaches are often based on costing and environmental assessment, needing a significant amount of data.

Few works consider the customer perspective in early phases of PSS design [6, $1,10,12]$, in which data is rather scarce, increasing the complexity of the decision process. Here, decision aiding approaches are mostly based on the judgement of actors and general aspects of the offer are described qualitatively. However, these researches are carried out within a structured decision situation, in which there is a clear set of PSS alternatives proposed by a given provider. Under this panorama, there is a gap in the literature of PSS design about early decision making from the customer perspective (i.e., criteria prioritization), when there is not a predefined set of alternatives. AHP can be used to prioritize the evaluation 
criteria for PSS design, before dealing with the choice of an alternative [4]. Next section explains AHP, which is a judgement-based method extensively used for unstructured decision contexts, and that will be explored in this research.

\section{AHP for early stages of PSS design}

Analytical Hierarchy Process (AHP) is a MCDA method introduced by Thomas Saaty [7]. The main base of AHP is psychological, seeking at integrating actors' judgement to the decision process. AHP aims at systematizing actors' subjectivity instead of eliminating it [7]. It consists on two main phases: modelling and evaluation. The modelling phase aims at structuring the problem in a hierarchy. It involves goals, criteria and alternatives. The evaluation phase performs a pair comparison between the elements of each level of the hierarchy, by using an ordinal scale (Table 1) [7]. The process of pair comparison takes into account the following mathematics rules [7]. For $n$ elements, a matrix $A \in \mathbb{R}^{n \times n}$ of comparisons is obtained, which is positive and reciprocal. Only $n \times(n-1) / 2$ comparisons $a_{i j}$ are needed, taking into account that $a_{i i}=1$ and $a_{i j}=1 / a_{j i}, \forall i \in\{1, \cdots, n\}$. As explained in [4], this process results in a judgements' matrix $A$ for each category of comparison. For calculating the weights it is necessary to normalize the values on the columns of $A$, then calculate the average of the rows, obtaining the called eigenvector or vector of priorities [7].

From the theoretical point of view, AHP is based on three main axioms:

1. Homogeneity: elements in the same category should be comparable.

2. Hierarchy: elements in each level of the hierarchy should be independent.

3. Reciprocity: expressed as $a_{i j}=1 / a_{j i}$

AHP does not need quantitative data to effectuate the evaluation process, since it is based on value judgements of actors. Furthermore, it allows to integrate several actors in the decision process and consider the problem context [7]. Thus, in early stages of PSS design, it appears to be suitable. Using this method for preliminary decision aiding enables two main benefits: i. Illustrating actors priorities (i.e., weighting evaluation criteria) and their compatibility, and ii. Verifying the adequacy of the current problem representation (i.e., hierarchical model constituted by value dimensions, criteria, and alternatives).

Table 1. Scale of preferences of AHP [7].

\begin{tabular}{c|c}
\hline Importance level of $i$ over $j$ & Verbal scale \\
\hline 1 & $i$ and $j$ are equally important \\
3 & Weak preference of $i$ over $j$ \\
5 & Net preference of $i$ over $j$ \\
7 & Very strong preference of $i$ over $j$ \\
9 & Absolute preference of $i$ over $j$ \\
\hline
\end{tabular}




\section{The case of a French company}

In this paper we analyse the case of a large-sized company in France, which will be designated as ' $C$ ' for confidentiality reasons. $C$ main activity is the production and distribution of energy. One of the most important activities of support of the company is the provision of safety clothing for its employees. Currently, the safety clothes belong to the employees, who are fully responsible for their usage, maintenance and recycling. This process introduces a lack of information in the company about the performance of the safety clothing system during the middle of life (MOL) and end of life (EOL) phases. Given this situation, $C$ launched a two-years project (2017-2019) of innovation. The aim of this project is to transform the current offer by considering its entire life cycle, moving from a product-based offer towards a PSS offer. Since the project is about the early design phase of a PSS, $C$ faces several decisions involving internal and external actors. As the project is in the context of purchasing decisions for innovative offers, the prioritization of the selection criteria is a major condition. AHP has been used in purchasing decision in several contexts [3]. In this particular context, AHP facilitates the task of experts in manifesting their preferences for sustainability criteria, following a collaborative approach.

\subsection{The collaborative process in $C$}

The research project is structured in three main phases. i. Structuring of the decision situation, ii. Identifying feasible business models based on PSS, and iii. The transformation of $C$ purchasing strategy. Currently, the methodology scope covers the first and second phases, and can be summarized as follows from a practical point of view:

Intervention with internal actors: workshop with the employees from the departments of Human Resources (HR), Purchasing, Prescription, Research $\&$ Development (R\&D) and Sustainable Development (SD). The aim of this step is setting the objectives and expectations of $C$.

Intervention with external actors: workshop with key contractual and potential providers, belonging to the fields of confection, transportation, maintenance (washing) and end of life treatment. The aim is understanding providers' expectations and capabilities to answer $C$ needs.

Decision situation structuring: collaborative workshop between internal and external actors to identify potential alternatives responding to $C$ needs, and formalize the criteria of evaluation.

\subsection{AHP application in $C$}

Since $C$ is interested in reviewing the entire value chain associated to the safety clothing, the decision situation has been broken down into the three main life cycle stages of the offer: beginning of life (BOL), middle of life (MOL) and end of life (EOL). Given this holistic approach, the project involves several internal 
and external actors. Internal actors belong to the departments of Purchasing (project coordinator), Prescription, Sustainable Development, and Human Resources. External actors are confectioners, logistics providers, washing service providers, EOL service providers, and social and environmental organizations. In the following, the decision situation of $C$ will be explained from the highest level of abstraction to the lowest one, shaping the hierarchical structure proposed by AHP.

Level 1 - Definition of the dimensions of value creation. The first level of reasoning corresponds to the identification of the main objectives linked to the decision process. Five main categories were identified, called "value dimensions". They are linked to $C$ 's expected benefits. The five value dimensions have been defined in collaboration with the internal actors since the beginning of the project, and they are supported by literature review on PSS and value co-creation. The value dimensions are defined as follows:

(E) Economics: refers to the economic benefits and costs for each stakeholder along the offer life cycle.

(N) Environmental: concerns the environmental impact of the offer, involving resources consumption, and emissions to the air, soil, and water.

(S) Social : considers the contribution to the well-being of the internal and external stakeholders.

(R) Relational: refers to the value derived from the quality of the relationships between the actors (i.e., enabling the common construction of knowledge).

(F) Functional: refers to the level of fitness between the offer functions and the customer expectations.

Level 2 - Design of evaluation criteria. The evaluation criteria were designed during an internal seminar conducted towards end of 2018. It involved a collaborative work of four groups formed by employees from the key departments of $C$ (HR, R\&D, SD, Purchasing and Prescription). Each group identified a set of criteria for each value dimension, establishing the link with $C$ strategy. The criteria were analysed and synthesized by the research group, in collaboration with $C$ for its validation. Table 2 shows the list of the social criteria.

Level 3 - Identification of Alternatives. The second seminar was conducted with the providers (Dec. 2018). The actors worked collaboratively to generate ideas about possible alternatives fitting $C$ 's objectives. Individual interviews were carried out with 11 providers to detail the offers. It was possible to draw out the decision focus for each stage of the life cycle. For the BOL, the main decision concerns the type of fibre to manufacture the safety clothes. Decisions on the MOL focus on the washing system and the type of technology for ensuring the clothes traceability. For the EOL, decisions concern the system for waste revaluation. The interviews resulted on a first overview of potential alternatives. 
Table 2. Social criteria (S) of $C$.

\begin{tabular}{|c|c|}
\hline Criterion & Description \\
\hline $\begin{array}{l}\text { S.1 - Social } \\
\text { performance of } \\
\text { providers }\end{array}$ & $\begin{array}{l}\text { Social evaluation of the provider according to the } \\
\text { provider auditory carried out by } C \text {. }\end{array}$ \\
\hline $\begin{array}{l}\text { S.2 - Employees } \\
\text { resistance }\end{array}$ & $\begin{array}{c}\text { Measure the degree of resistance (to change) of } \\
\text { employees to choose one alternative over another } \\
\text { regarding the clothing system. Score obtained through } \\
\text { a satisfaction survey. }\end{array}$ \\
\hline $\begin{array}{l}\text { S.3 - Solidarity } \\
\text { purchasing }\end{array}$ & $\begin{array}{c}\text { Service purchasing to the SAP regarding washing, } \\
\text { maintenance and end of life treatment of the safety } \\
\text { clothes. }\end{array}$ \\
\hline $\begin{array}{l}\text { S. } 4 \text { - Local job } \\
\text { generation }\end{array}$ & $\begin{array}{c}\text { Number of new local jobs created from the new } \\
\text { clothing system. }\end{array}$ \\
\hline
\end{tabular}

Performing AHP evaluation. The data was computed automatically with $R$ software, using the AHP library. The weights were calculated for each stage of the life cycle. The evaluation process relies on the use of questionnaires answered by the internal actors of $C$. Six actors from different departments were chosen, having a good knowledge about the project. The questionnaires are answered with the guidance of the research team involved in the project. Table 3 shows the criteria weighting obtained from the Purchasing department.

\section{Discussion}

Based on Table 3 it is possible to highlight some preliminary conclusions about the preferences of Purchasing department. First, the economic dimension is a priority for all the stages of the life cycle. Second, the functional dimension is the most important aspect in the beginning of life(BOL), which is explained by the primary importance of keeping employees safe; however, this dimension is rather insignificant in the middle and end of life. Third, environmental and social dimensions have similar importance in the middle and end of life. This can be explained by the interest of $C$ of reducing long-circuits purchasing (i.e., re-locating production in France), and a good knowledge of the market in these phases of the life cycle. However, the importance of the environmental dimension in the EOL is the lowest among all the dimensions, which would be explained by the lack of knowledge regarding this phase, combined with a misinterpretation of the environmental criteria. Finally, the relational dimension is the less important one from the Purchasing department perspective, focusing in the brand image.

There is a general consistency in the judgements, excepting the social dimension, in which inconsistencies exceed the maximum allowed level for AHP $(I<$ 0.1 ). These inconsistencies indicate a misunderstanding of the social criteria, explained by their high level of abstraction. From this evaluation, it is possible to realize the need of clarifying some criteria, specially the abstract ones as 
Table 3. Preliminary criteria weights in each life cycle stage in $C$.

\begin{tabular}{lcccccc}
\hline Criterion & BOL $^{a}$ & $\boldsymbol{I}^{b}$ & MOL & $\boldsymbol{I}$ & EOL & $\boldsymbol{I}$ \\
\hline E - Economic & $\mathbf{3 2 . 8 \%}$ & $\mathbf{0 . 0 \%}$ & $\mathbf{4 2 . 4 \%}$ & $\mathbf{0 . 0 \%}$ & $\mathbf{5 9 . 4 \%}$ & $\mathbf{0 . 0 \%}$ \\
E.1 - Life cycle cost & $28.7 \%$ & $0.0 \%$ & $37.1 \%$ & $3.7 \%$ & $52.0 \%$ & $3.7 \%$ \\
E.2 - Purchasing cost & $4.1 \%$ & $0.0 \%$ & $5.3 \%$ & $0.0 \%$ & $7.4 \%$ & $0.0 \%$ \\
N - Environmental & $\mathbf{1 5 . 2 \%}$ & $\mathbf{0 . 0 \%}$ & $\mathbf{1 6 . 9 \%}$ & $\mathbf{0 . 0 \%}$ & $\mathbf{4 . 5 \%}$ & $\mathbf{0 . 0 \%}$ \\
N.1 - Fiber env. quality & $12.7 \%$ & $0.0 \%$ & - & - & - & - \\
N.2 - Provider env. perf. & $2.5 \%$ & $0.0 \%$ & - & - & - & - \\
N.3 - Chemical use & - & - & $14.8 \%$ & $0.0 \%$ & - & - \\
N.4 - Carbon footprint & - & - & $2.1 \%$ & $0.0 \%$ & $0.8 \%$ & $0.0 \%$ \\
N.5 - Recycling rate & - & - & - & - & $3.7 \%$ & $0.0 \%$ \\
R - Relational & $\mathbf{4 . 5 \%}$ & $\mathbf{0 . 0 \%}$ & $\mathbf{1 5 . 8 \%}$ & $\mathbf{0 . 0 \%}$ & $\mathbf{7 . 9 \%}$ & $\mathbf{0 . 0 \%}$ \\
R.1 - Brand image & $3.7 \%$ & $0.0 \%$ & $13.8 \%$ & $0.0 \%$ & $6.9 \%$ & $0.0 \%$ \\
R.2 - Innovation sharing & $0.8 \%$ & $0.0 \%$ & $2.0 \%$ & $0.0 \%$ & $1.0 \%$ & $0.0 \%$ \\
S - Social & $\mathbf{1 2 . 9 \%}$ & $\mathbf{0 . 0 \%}$ & $\mathbf{1 5 . 0 \%}$ & $\mathbf{2 8 . 1 \%}$ & $\mathbf{2 3 . 2 \%}$ & $\mathbf{4 1 . 5 \%}$ \\
S.1 - Provider social perf. & $1.6 \%$ & $0.0 \%$ & - & - & - & - \\
S.2 - User resistance & $11 \%$ & $0.0 \%$ & $10.3 \%$ & $0.0 \%$ & $15.6 \%$ & $0.0 \%$ \\
S.3 - Solidarity purchasing & - & - & $3.5 \%$ & $0.0 \%$ & $1.6 \%$ & $0.0 \%$ \\
S.4 - Local job generation & - & - & $1.2 \%$ & $0.0 \%$ & $6.0 \%$ & $0.0 \%$ \\
F - Functional & $\mathbf{3 4 . 6 \%}$ & $\mathbf{0 . 0 \%}$ & $\mathbf{9 . 8 \%}$ & $\mathbf{0 . 0 \%}$ & $\mathbf{5 . 3 \%}$ & $\mathbf{0 . 0 \%}$ \\
F.1 - Fiber quality & $17.3 \%$ & $0.0 \%$ & - & - & - & - \\
F.2 - Availability & $17.3 \%$ & $0.0 \%$ & - & - & - & - \\
F.3 - Comfort & - & - & $7.3 \%$ & $0.0 \%$ & - & - \\
F.4 - Clothing lifespan & - & - & $2.0 \%$ & $0.0 \%$ & - & - \\
F.5 - Traceability efficiency & - & - & $0.5 \%$ & $0.0 \%$ & - & - \\
\hline
\end{tabular}

${ }^{a}$ BOL: beggining of life; MOL: middle of life; EOL: end of life.

${ }^{b}$ Consistency ratio.

relational and social. The remaining evaluations should provide enough evidence to get a well-structured set of priorities of value dimensions and criteria. At least, two possible scenarios could take place, i. the evaluations are completely divergent, and ii. the evaluations show a clear convergence between actors' perspectives. In the first case, it is no possible to get reliable conclusions, and a redefinition of the model and the decision approach should be considered. In the second case, small modifications of the model are required, and it is possible to draw out some conclusions about the criteria priorities.

\section{Conclusions}

This paper presents an atypical problem of design in the domain of Product-Service Systems (PSS), in which the innovation is triggered by the customer, without any knowledge about possible alternatives. The main intent of this research is to provide a supporting methodology for systematize the decision process in a highly unstructured situation for early PSS design. This 
facilitates the co-creation process between the customers and providers. Here, the AHP approach, based on actors' judgements, provides a frame to structure such a complex decision situation. A correct application of AHP requires domain specific knowledge, the understanding of the potentialities and limits of the methodology, and a good representation of the elements to be analysed. This approach helped to clarify the points of view of the key actors and their compatibility. The output of this work is a semi-structured decision model to support the early phases of PSS design in company $C$, providing the weights of criteria and value dimensions. In the next phase of the project, a multi-criteria decision approach should be used to compare a set of alternatives.

\section{References}

1. Bertoni, A., Bertoni, M., Johansson, C.: Analysing the effects of value drivers and knowledge maturity in preliminary design decision-making. In: Design Information and Knowledge Management. International Conference on Engineering Design, Design Society (2015)

2. Dahmani, S., Boucher, X., Peillon, S., Besombes, B.: A reliability diagnosis to support servitization decision-making process. Journal of Manufacturing Technology Management 27(4), 502-534 (2016)

3. Mani, V., Agrawal, R., Sharma, V.: Supplier selection using social sustainability: Ahp based approach in india. International Strategic Management Review 2(2), $98-112(2014)$

4. Medini, K., Cunha, C.D., Bernard, A.: Tailoring performance evaluation to specific industrial contexts application to sustainable mass customisation enterprises. International Journal of Production Research 53(8), 2439-2456 (2015)

5. Neubert, G., Lambey-Checchin, C.: The sustainable value proposition of PSSs: The case of ECOBEL "Shower Head". Procedia CIRP 47, 12-17 (2016)

6. Rondini, A., Bertoni, M., Pezzotta, G.: An IPA based method for PSS design concept assessment. Procedia CIRP 64, 277-282 (2017)

7. Saaty, T.L.: How to make a decision: The analytic hierarchy process. European Journal of Operational Research 48(1), 9-26 (1990)

8. Schmidt, D.M., Malaschewski, O., Mrtl, M.: Decision-making process for product planning of product-service systems. Procedia CIRP 30, 468-473 (2015)

9. Shen, J., Erkoyuncu, J.A., Roy, R., Wu, B.: A framework for cost evaluation in product service system configuration. International Journal of Production Research 55(20), 6120-6144 (2017)

10. Song, W., Ming, X., Han, Y., Wu, Z.: A rough set approach for evaluating vague customer requirement of industrial product-service system. International Journal of Production Research 51(22), 6681-6701 (2013)

11. Song, W., Sakao, T.: A customization-oriented framework for design of sustainable product/service system. Journal of Cleaner Production 140, 1672 - 1685 (2017)

12. Song, W., Sakao, T.: An environmentally conscious PSS recommendation method based on users' vague ratings: A rough multi-criteria approach. Journal of Cleaner Production 172, 1592-1606 (2018)

13. Zhang, W., Guo, J., Gu, F., Gu, X.: Coupling life cycle assessment and life cycle costing as an evaluation tool for developing product service system of high energy-consuming equipment. Journal of Cleaner Production 183, 1043-1053 (2018) 